\title{
Best practices for comprehensive tobacco control programs: opportunities for managed care organisations
}

\author{
Michael P Eriksen
}

I shall begin with an overview of the Centers for Disease Control and Prevention's (CDC) Office on Smoking and Health and the evolution of its important relationship with the managed care world over the past few years.

Dr Jeffrey Koplan, previously head of the National Center for Chronic Disease Prevention and Health Promotion, in which the Office on Smoking and Health is housed, became the new director of the CDC in October 1998. Two of his priorities for the agency are strengthening the science base for public health action and collaborating with health care partners for prevention. A primary reason for my presence at this meeting was to reinforce this acknowledgment that we cannot accomplish our public health objectives without working closely with our health care partners; managed care organisations (MCOs) are critical in this regard. And one of the first collaborations between the CDC and MCOs was on reducing tobacco use.

During a meeting between CDC and its public health partners held in Atlanta in 1995, participants examined the issue of how MCOs and health maintenance organisations (HMOs) could become more involved with programs to reduce tobacco use. ${ }^{1}$ Rather than highlighting cessation at this meeting, we tried to take a broader public health view towards tobacco control by identifying various policy interventions in which MCOs can involve themselves, including prevention, minors' access, school programs, and treatment activities. We also discussed the role MCOs could play related to clean indoor air policies, not only within managed care health facilities (which hopefully were all smoke free in 1995 and certainly are now) but also in terms of helping communities pass laws that would protect non-smokers from the adverse effects of second hand smoke (also called environmental tobacco smoke (ETS)).

Additionally, we discussed the effects of tobacco industry advertising and of counteradvertising, the importance of economic incentives to reduce tobacco use, and the issue of product regulation. At the state level great progress has been made in increasing tobacco related restrictions and raising excise taxes as a means to decrease tobacco consumption. State initiatives have also occurred within the area of product regulation, despite having been considered primarily a federal responsibility. Massachusetts has led the way, holding the industry accountable for a product that includes tar, nicotine, and other harmful ingredients, although the industry has challenged these efforts in the courts.
As a result of the 1995 meeting, we initiated a cooperative agreement with what was at the time called "The HMO Group" to fund counteradvertising activities, and we solicited MCOs to become involved. The premise was to allow MCOs to explore expansion of tobacco control efforts beyond the realm of clinical interventions such as the nicotine "patch" and other smoking cessation aids. Two MCOs participated, beginning with Kaiser Permanente in Colorado, which demonstrated impressive results. Last year, the organisation presented the data from their program in the journal Tobacco Control. ${ }^{2}$ The second MCO involved in the project was Group Health Northwest, which conducted education and media based interventions to reduce tobacco use among its members.

We have been very pleased by these early results, and we are looking forward to continuing our partnerships with MCOs, as well as with the Robert Wood Johnson Foundation (RWJF), the Agency for Healthcare Research and Quality (formerly the Agency for Health Care Policy Research), the National Cancer Institute (NCI), and others. We are particularly excited about the initiative under RWJF's leadership to emphasise tobacco control in MCOs.

\section{Tobacco control in public health}

I now wish to discuss where we are today in terms of tobacco control in public health, and how MCOs can fit within this dynamic. This year, the funding for the ASSIST (American Stop Smoking Intervention Study for Tobacco prevention) project is moving from NCI to CDC, which will begin funding all 50 states and the District of Columbia for tobacco control. We have developed a framework that represents how CDC will be approaching the funding of state based tobacco control programs (table 1). The model addresses four goals for tobacco control: (1) preventing initiation of tobacco use by young people; (2) promoting cessation among young people and adults; (3) eliminating non-smokers' exposure to ETS; and (4) identifying and eliminating disparities related to tobacco use and its adverse effects among different population groups.

We encourage states to use this model and have asked that as states develop their plans to achieve these four goals, they rely on state and community interventions, countermarketing activities, policy and regulatory change, and surveillance and evaluation efforts. We are also requesting states to plan their initiatives according to how they prioritise among the four goals. To encourage as robust an agenda as possible with our state program, the Office on Smoking 
Table 1 Components and goals for a national tobacco control program framezork

\begin{tabular}{|c|c|c|c|c|}
\hline \multirow[b]{2}{*}{ Components } & \multicolumn{4}{|l|}{ Goals } \\
\hline & $\begin{array}{l}\text { Prevent initiation } \\
\text { among youth }\end{array}$ & $\begin{array}{l}\text { Promote quitting } \\
\text { among adults }\end{array}$ & $\begin{array}{l}\text { Eliminate } \\
\text { exposure to } \\
\text { ETS }\end{array}$ & $\begin{array}{l}\text { Identify and eliminate } \\
\text { disparities among } \\
\text { populations }\end{array}$ \\
\hline
\end{tabular}

Community interventions

Countermarketing

Policy/legislation

Surveillance/ evaluation be spent on tobacco control or public health in general. Money can be spent on anything a state chooses. Among state officials, current plans range from wanting to spend the money on public health, to wanting to sell the award to an investment banking firm and use the return to settle the state's debt. The more people realise how much money is available, the more attempts are made to earmark the monies to build prisons, repair roads, pay for indigent care, or give taxpayers a rebate on state taxesworthy uses, but unrelated to tobacco control or to public health in its usual sense. towards this effort. We are also urging states to work collaboratively with MCOs to achieve an optimal effect with these funds.

\section{Federal activities}

Next, I will highlight some of the federal level activities related to issues announced by the President in his most recent State of the Union address. The President has outlined a tobacco control agenda comprising various fiscal mechanisms that could greatly impact the tobacco industry. First, the President announced he will make a recommendation for a fairly substantial increase in the federal excise tax-we believe an additional 55 cents. Although this amount is less than the $\$ 1.00$ to $\$ 1.10$ discussed last year, it is still more than twice the current federal excise tax. Congressional approval will be required, however.

Second, the President directed Attorney General Reno to initiate a process to sue the tobacco industry for recoupment of federal Medicare payments. We estimate that the federal Medicare payments attributable to smoking related diseases range from $\$ 10$ billion to $\$ 20$ billion per year-larger than all the recoveries from all the state settlements with the tobacco industry combined.

A third measure is the federal government's claim to recover from the nearly $\$ 250$ billion received by states (the $\$ 40$ billion that went to the four states that made individual settlements, as well as the $\$ 206$ billion from the other 46 states' Master Settlement Agreement reached in November) its portion of the state Medicaid awards, which averages nationally at $57 \%$. Driving this effort is a federal statute that obligates the government to recover such Medicaid reimbursements. If the federal government does not pursue this recovery, it could be sued for failing to fulfill its fiduciary responsibility. However, the National Governors' Association, the National Conference of State Legislators, and Congress have indicated their intent to oppose this effort. The coming months will likely see a dynamic argument evolving over whether and to what extent the federal government should or is able to seek recovery of these state awards.

On this issue of federal versus state claims, some observers have argued, in so many words, "Let the states have the dollars. They filed suit. They deserve the money, and they can do a better job of spending the money on tobacco control in public health". We feel that, in a sense, this may be the case. However, neither the individual state settlements nor the Master Settlement Agreement requires any dollars to

\section{Guidelines for tobacco control programs} Our office has responded to this potential increase in resources available for tobacco control by developing guidelines for model state based tobacco control programs. ${ }^{3}$ We have identified nine components of a comprehensive tobacco control program and have estimated state specific ranges for amounts that should be spent in each of these nine categories to achieve a measurable difference in reducing tobacco use (table 2). These guidelines draw upon best practices determined: (1) by evidence based analyses of state programs funded by increased tobacco excise taxes in California and Massachusetts; and (2) by CDC's involvement in planning comprehensive tobacco prevention and control programs in other states with excise tax funded programs. California and Massachusetts have demonstrated great innovation in tobacco control, and evidence suggests a linear relationship between investment and outcome.

PROGRAMS TO REDUCE TOBACCO USE

Although all nine components are important, we regard community based programs to reduce tobacco use as the most essential. Achieving the individual behaviour change that supports the non-use of tobacco requires whole communities to change the way tobacco is promoted, sold, and used, while changing the knowledge, attitudes, and practices of young people, tobacco users, and non-users. CDC currently provides states approximately 20 cents per capita for tobacco control efforts. To fund a comprehensive tobacco control program, we recommend that states spend settlement dollars or excise tax funds at a level approaching $\$ 5$ to experiences of Massachusetts and California, we expect to observe a rapid acceleration in the reduction of tobacco use. Further, evidence suggests that resources must reach the local level to achieve such community involvement and to sustain change. California and Massachusetts have experienced a two to three times greater

Table 2 CDC's recommended components for a comprehensive, state level tobacco control program

- Programs to reduce tobacco use

- Programs to reduce the burden of tobacco related diseases

- School programs

- Enforcement

- Partnership grants

- Countermarketing

- Cessation

- Surveillance and evaluation

- Administration and management $\$ 20$ per capita. At this level, judging by the 


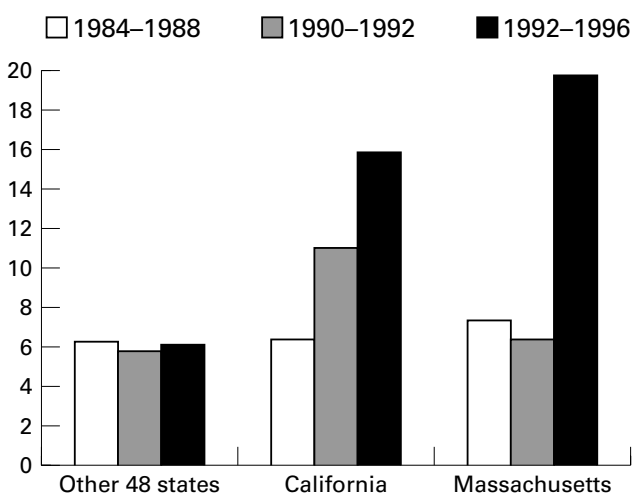

Figure 1 Decrease in per capita cigarette consumption before and after a tobacco excise tax increase and an anti-smoking campaign in California and Massachusetts compared with decrease in other 48 states overall, 1984 to 1996.

reduction in tobacco consumption than the rest of the country because they have been able to direct resources to the local level (fig 1).

PROGRAMS TO REDUCE THE BURDEN OF TOBACCO RELATED DISEASES

Another element of community programs takes into account how tobacco use increases the risk of developing a number of diseases. Even if current tobacco use is stopped, the residual burden of disease among past users would cause disease for decades in the future. Community programs can focus attention directly on these tobacco related diseases, both to help prevent their occurrence and to detect them early. When supported at a comprehensive level, state based tobacco prevention and control programs can address diseases for which tobacco is a major cause, such as cardiovascular disease, cancer, stroke, oral cancers, and asthma. These programs offer an opportunity for MCOs to become involved by expanding their efforts toward preventing and detecting disease.

SCHOOL PROGRAMS

The third area involves school programs. Because most people who start smoking are younger than age 18, school based programs that prevent the onset of smoking are a crucial part of a comprehensive program to prevent tobacco use. Several studies have shown that school based tobacco prevention programs, which identify the social influences that promote tobacco use among youth and teach skills to resist such influences, can significantly reduce or delay adolescent smoking. The CDC has developed guidelines for comprehensive school based tobacco control programs, and we have been aggressively promoting evidence based models, such as the life skills training program by Gil Botvin of Columbia University. However, greater effort is needed to implement effective programs.

ENFORCEMENT

Another area of emphasis is the enforcement of tobacco control policies, which enhances their efficacy both by deterring violations and by sending a message to the public that community leadership strongly supports the policies. The two primary areas addressed by local and state policies requiring enforcement strategies are restrictions related to minors' access to tobacco and clean indoor air. Presently, states vary greatly in their ability to prevent the sale of tobacco to kids. A model example is Florida, which established a licensing program for tobacco products, administered by the Alcohol and Beverage Commission. When outlets are inspected for sale of alcohol, the sale of tobacco products is also included. Revenue from the licences is used to hire inspectors. As a result, Florida has been able to achieve an illegal sales rate of $7 \%$. MCOs should become involved in efforts to increase enforcement of minors' access laws and pass state and local ordinances for clean indoor air. MCOs should also encourage parents to provide smoke free environments for their children.

PARTNERSHIP GRANTS

The next area, partnership grants, is perhaps where MCOs can play the largest role. Statewide projects can increase the capacity of local programs by providing technical assistance on program evaluation, promotion of media advocacy, implementation of smoke free policies, and reduction of minors' access to tobacco. Supporting organisations that have statewide access to diverse communities can help eliminate the disparities in tobacco use among the state's various population groups. State based medical associations, minority health networks, and other types of organisations that can help reach these groups should be funded. California and Massachusetts have both funded statewide organisations and regional non-governmental entities that reach out specifically to youth, women, minority organisations, and blue collar workers. Managed care groups can become involved in this coordinated effort by providing access to populations within the state or to those populations which cross state boundaries.

COUNTERMARKETING

Another component of a comprehensive program is countermarketing. This element involves paid advertising campaigns to counter the $\$ 5$ billion each year that the tobacco industry spends to market and promote tobacco use. Countermarketing activities can promote smoking cessation and decrease the likelihood of initiation. In addition, countermarketing messages can have a powerful influence on public support for tobacco control intervention and establish a supportive climate for school and community efforts. Although we have experienced an entire generation of misinformation and lies glamourising tobacco, states such as Arizona, Florida, Massachusetts, and California have developed innovative anti-tobacco messages. When these ads are shown as a part of a comprehensive tobacco control program, the effects are quite positive. Countermarketing presents another opportunity for MCOs to become involved, whether by sponsoring anti-tobacco messages or simply by excluding waiting room magazines that include tobacco advertisements.

\section{CESSATION}

Another component consists of treatment programs for nicotine addiction. These 
programs can produce quicker and probably larger short term public health benefits than any other component of a comprehensive tobacco control program. However, this area has received limited attention and has lacked proper models from which to demonstrate effectiveness. The Agency for Healthcare Research and Quality has published evidence based clinical practice guidelines on cessation. Model programs in large managed care plans show that full implementation of these guidelines, in conjunction with efforts to minimise access and cost barriers, increases the use of proven treatments and decreases smoking prevalence. Health Partners Research Foundation and Group Health of Puget Sound are two examples of MCOs that have implemented treatment programs and conducted cessation related research.

SURVEILLANCE AND EVALUATION

The next to last component is surveillance and evaluation, which is necessary to determine if progress is being achieved and to hold programs accountable for the money they spend. We strongly believe that success in tobacco control requires a commitment to measure and monitor changes that may take place. We must examine changes in behaviour, as well as changes in attitudes, beliefs, and intentions.

The tobacco industry knows much more about smoking patterns than we do. We recently met with representatives from Philip Morris, who wanted to show us their new $\$ 100$ million youth campaign to decrease smoking among youth. During the meeting, the representatives stated they would be launching their own survey to monitor youth behaviour and attitudes regarding smoking. They would conduct these surveys regularly, as they now do for adults. In fact, the tobacco industry conducts surveys on all but two days of the year-New Year's Day and the Great American Smokeout day, both being times when many smokers try to quit. Every other day, the tobacco industry is asking smokers how many cigarettes they smoke, what type of cigarettes they smoke, and what brands they prefer. They will do the same with kids as part of their effort to reduce smoking among youth.

We see the surveillance and evaluation component as the evidence based determination of what is working, or essentially an applied research model. We did not include research in our framework, partly because we saw it primarily as a federal responsibility; however, we encourage states to engage in research of an applied nature.

ADMINISTRATION AND MANAGEMENT

The last element of an effective tobacco control program is a strong management structure. Experience in other states has shown the importance of having all of the program components coordinated and well managed. Because a comprehensive program involves multiple state and local agencies, as well as numerous voluntary and community organisations, program administration and management is vital to the success of the program.
Table 3 Budget summary guidelines for comprehensive, state level tobacco control programs

- $\$ 7$ to $\$ 20$ per capita in smaller states

(population under 3 million)

- $\$ 6$ to $\$ 17$ per capita in medium sized states (population 3 to 7 million)

- $\$ 5$ to $\$ 16$ per capita in larger states (population over 7 million)

As for resources for tobacco control, we suggest that a range from $\$ 7$ to $\$ 20$ per capita be invested in comprehensive tobacco control programs in smaller states, from $\$ 6$ to $\$ 17$ in medium states, and from $\$ 5$ to $\$ 16$ in larger states (table 3). Again, we do not know whether this will happen. These funding levels would account for $22-55 \%$ of the average payment states receive from tobacco industry settlements. Organisations such as the Campaign for Tobacco-Free Kids and the American Public Health Association are lobbying Congress and states to spend up to $30 \%$ of their awards for tobacco control. This higher value fits within the CDC's recommendations.

Relating back to the federal government's effort to claim part of the state awards received as Medicaid recoupment, there have been some discussions regarding legislation introduced in Congress that would prohibit the federal government from pursuing these funds if, in fact, states spend them in certain ways. Some are advocating for directing a proportion of resources towards tobacco control. The model presented here is CDC's effort to provide an evidence based approach to this end.

\section{Conclusion}

In conclusion, we are excited about the recent activities occurring within the sphere of tobacco control, and we see various opportunities to increase our collaboration with managed care. In addition to the efforts MCOs can make through cessation and other clinical activities, they can also play an important role in community based tobacco control, for their constituents as well as for the communities in which they operate. We deeply encourage MCOs to become active and powerful advocates of effective, comprehensive programs to prevent and control tobacco use.

Since the time of this presentation, the federal government has filed a lawsuit against the tobacco industry for Medicare reimbursement, which is scheduled for trial in January 2003. The President continued to call for federal excise tax increases, but none has been approved by Congress. The federal effort to recover a portion of state Medicaid awards was also unsuccessful. Senator Hutchinson of Texas introduced an amendment prohibiting federal recoupment of state tobacco Medicaid awards.

\footnotetext{
1 Yox SB. Tobacco use prevention and reduction. HMO Prac-

tice: Fournal of the HMO Group 1995;9:123-7.
Seghers T, Foland S. Anti-tobacco media campaigns for young people. Tobacco Control 1998;7:S29-30.

3 Centers for Disease Control and Prevention. Best practices for comprehensive tobacco control programs-August 1999 . At comprehensive tobacco control programs-August 1999. Atlanta, Georgia: US Department of Health and Human Nates, Centers for Disease Control and Prevention, Promotion, Office on Smoking and Health, August 1999.
} 